\title{
Síndrome de Sweet en un paciente infectado con el VIH
}

\section{Sweet's syndrome in an HIV-infected patient}

\author{
Alessandra Ynes Pachas-Quiroz,' César Chian-García, \\ Juan Villarreal-Menchola ${ }^{3}$
}

Pachas-Quiroz AY, Chian-García C, Villarreal-Menchola J.Síndrome de Sweet en un paciente infectado con VIH. Rev Soc Peru Med Interna. 2018;32(2):59-62. https://doi.org//0.36393/spmi.v32i2.219

\section{INTRODUCCIÓN}

El síndrome de Sweet (SS) fue descrito por primera vez por Robert Douglas Sweet, en 1964, tras observar a ocho pacientes mujeres en el Hospital General de Plymouth. ${ }^{1}$ Entre 1949 y 1964 se describieron las cuatro características fundamentales para el diagnóstico de la enfermedad: fiebre; leucocitosis neutrofílica; erupción aguda en forma de placas y/o nódulos eritematosos y edematosos generalizados; infiltrado neutrofílico dérmico masivo sin vasculitis. El SS se ha descrito en todo el mundo sin predilección racial y es caracterizado por la aparición abrupta de fiebre, neutrofilia, lesiones eritematoso cutáneas e, histológicamente, por un infiltrado difuso de neutrófilos ubicado en la dermis superior.

La patogenia del SS aún no se ha dilucidado y se supone que es el resultado de una reacción de hipersensibilidad a un antígeno bacteriano, tumoral o viral. ${ }^{2}$ La fiebre y la leucocitosis periférica sugieren un proceso séptico. Se ha postulado que los autoanticuerpos circulantes, las citocinas, los dendrocitos dérmicos, los complejos inmunes, los serotipos de antígenos leucocíticos humanos y los mecanismos leucotácticos tienen un papel etiológico en el desarrollo de los síntomas.

El SS clásico tiene una fuerte predilección por el sexo femenino, pero este predominio a menudo carece de

I. Médica residente de medicina interna. Facultad de Medicina, Universidad Peruana Cayetano Heredia (UPCH). Hospital Nacional Arzobispo Loayza (HNAL).

2. Médico internista. Facultad de Medicina, UPCH. HNAL.

3. Médico patólogo. Facultad de Medicina, UPCH. HNAL. casos relacionados con malignidad. El SS comúnmente se presenta entre los 30 y 60 años, aunque se han reportado casos incluso en el período neonatal. ${ }^{3}$

El SS en la infección por el virus de inmunodeficiencia humana (VIH) es extremadamente raro y, hasta la fecha, hay pocos informes de casos..$^{4-6}$ Algunos autores consideran que las alteraciones inmunológicas inducidas por el VIH podrían desempeñar un papel importante como precipitante de esta dermatosis a través de la formación de inmunocomplejos con activación de polimorfonucleares neutrófilos.

Se presenta un caso del SS en una mujer con infección por VIH.

\section{PRESENTACIÓN DEL CASO}

Paciente de 46 años, natural y procedente de Lima, mestiza, soltera, evangélica y de ocupación comerciante ambulante. Antecedente de infección por VIH en tratamiento irregular con abacavir, $300 \mathrm{mg}$, lopinavir/ ritonavir, $200 \mathrm{mg} / 50 \mathrm{mg}$ y lamivudina, $150 \mathrm{mg}$, desde hace siete años.

Ingresó con un cuadro de cinco días de evolución caracterizado por aumento de volumen y lesiones papuloeritematosas en ambas manos, agregándose posteriormente lesiones en miembros inferiores, a predominio de las rodillas. Cuatro días antes del ingreso presentó imposibilidad para realizar actividades diarias, alza térmica no cuantificada, con dolor y aumento de volumen progresivo, de leve a moderada intensidad, de las lesiones por lo que acudió al servicio de Emergencia del Hospital Nacional Arzobispo Loayza. 


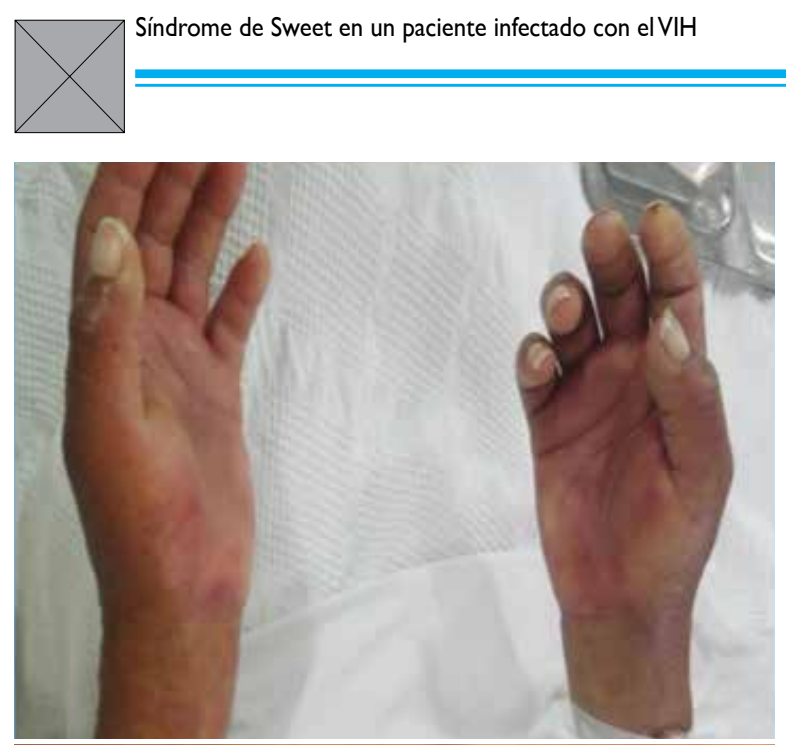

En el examen físico: Piel con pápulas eritematosas con aumento de volumen en ambas manos con signos de flogosis. Múltiples lesiones maculopapuloeritematosas en manos, rodillas y tórax (Figura 1).

\section{Exámenes auxiliares}

Hemoglobina 12,50 g/dL; leucocitos $12470 / \mathrm{mm}^{3}$ (abastonados $1 \%$, segmentados $72 \%$, eosinófilos $1 \%$, monocitos $9 \%$, linfocitos $17 \%$ ), plaquetas $522000 / \mathrm{mm}^{3}$. Tiempo de protrombina $1,9 \mathrm{~s}$; INR 1,18.

Glucemia $145 \mathrm{mg} / \mathrm{dL}$, creatinina $0,5 \mathrm{mg} / \mathrm{dL}$.

VDRL no reactivo, AgHBs negativo.

Examen completo de orina: leucocitos 2-5/campo, hematíes 5-10/campo.

Biopsia de las lesiones de piel. Anatomía patológica: Leve infiltrado intersticial mixto constituido por algunos neutrófilos y células mononucleares, hallazgos compatibles con SS. Figura 2.

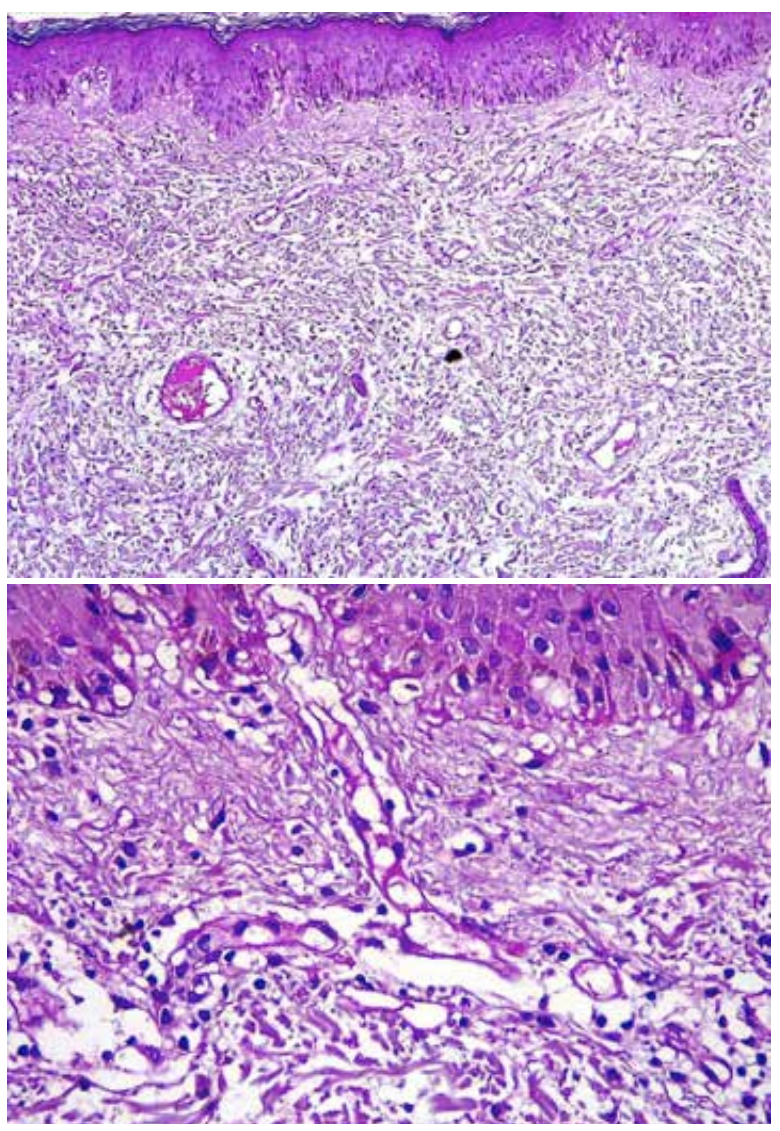

Figura 2. Leve infiltrado intersticial mixto constituido por algunos neutrófilos Figura I. Lesiones maculopapuloeritematosas. y células mononucleares. 


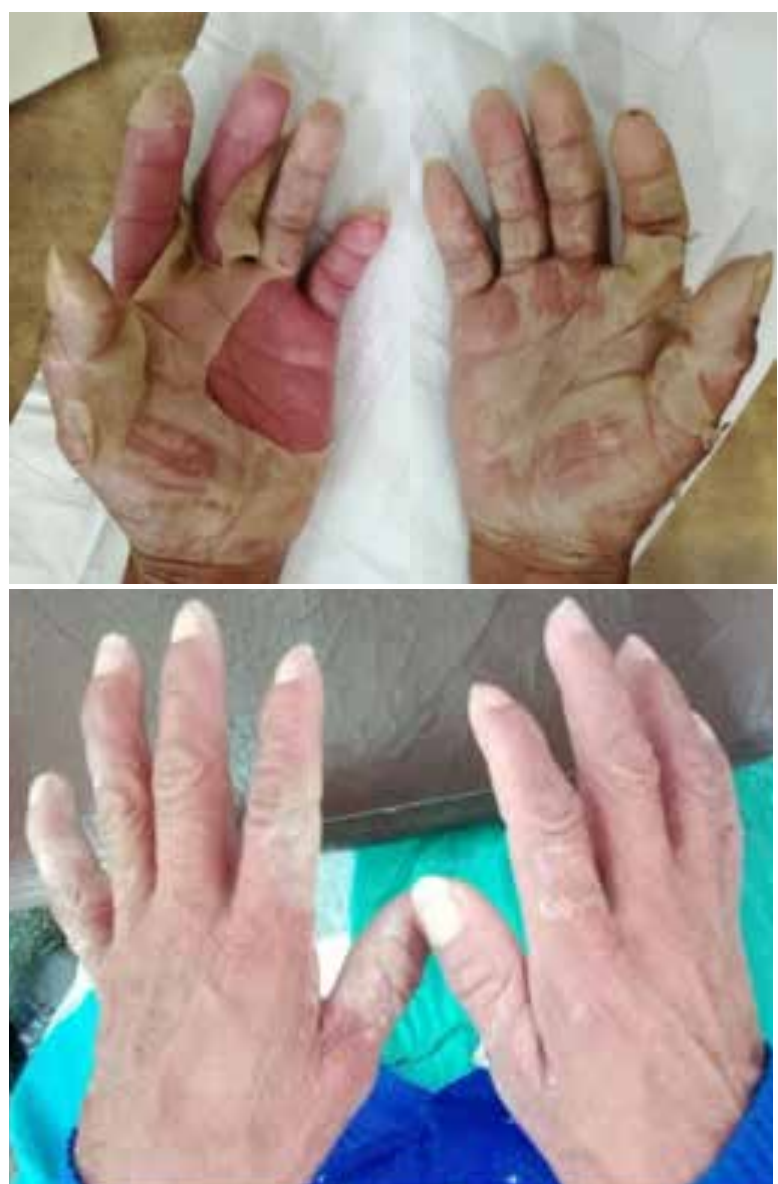

Figura 3. Evolución buena. Las lesiones de las manos se descamaron, y dejaron lesiones hipocrómicas.

Ante la sospecha inicial de un cuadro de dermatitis infectada probable, se inició un esquema de tratamiento con ciprofloxacino, $200 \mathrm{mg}$, EV, cada $12 \mathrm{~h}$, más clindamicina, $600 \mathrm{mg}, \mathrm{EV}$, cada $8 \mathrm{~h}$, durante un día, que se suspendió. Ya hospitalizada, presentó fiebre de $38^{\circ} \mathrm{C}$, durante dos días, para después tornarse afebril. Se empleó cetirizina, $10 \mathrm{mg}$, oral, cada $24 \mathrm{~h}$; betametasona, al $0,01 \%$, crema tópica; tramadol, $100 \mathrm{mg}, \mathrm{EV}$, cada $8 \mathrm{~h}$, con lo que se consiguió una mejoría paulatina.

La evolución de la paciente fue buena y fue dada de alta sin complicaciones. Las lesiones de las manos se descamaron, para, finalmente, dejar lesiones hipocrómicas (Figura 3).

\section{DISCUSIÓN}

El SS tiene alta asociación con cuadros tan sencillos como infecciones hasta casos más complejos como cuadros neoplásicos. ${ }^{7}$

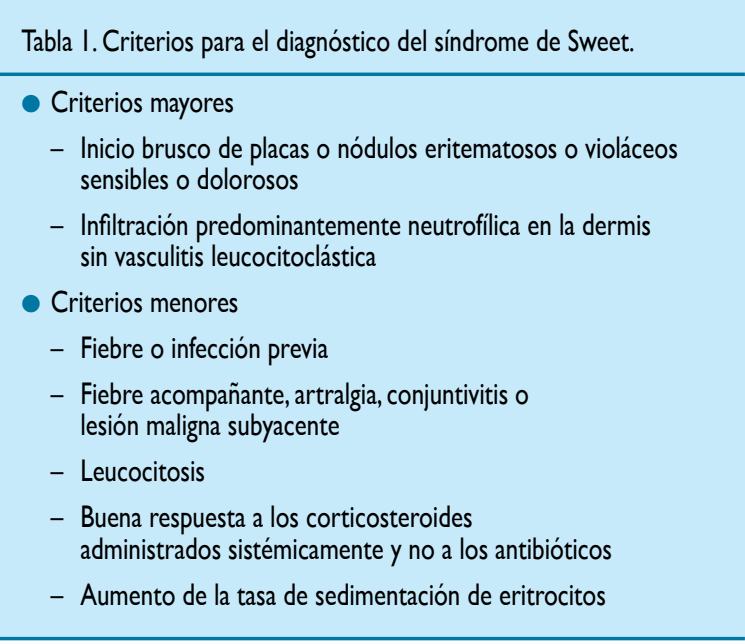

Los criterios para el diagnóstico de SS se propusieron originalmente en 1986. Más tarde fueron modificados por von den Driesch, en 1994. Para el diagnóstico se requieren criterios mayores y al menos dos criterios menores $^{8}$ (Tabla 1). La paciente del presente caso cumplía dos criterios mayores y tres menores.

La paciente tuvo una evolución favorable con la aplicación de corticoides tópicos, que, según la bibliografía revisada, está indicada. Dado que el SS puede ser de origen multifactorial, se plantea la posibilidad de compromiso del sistema inmunológico como activación de las células $\mathrm{T}$, que involucra a citocinas, lo que genera la activación y la infiltración de neutrófilos en la dermis; sin embargo, no es el único mecanismo implicado. Se ha descrito un caso de SS que fue fatal, con compromiso de arterias (sus fibras elásticas) como el de síndrome de Marshall (cardíaco), además de compromiso hepático. ${ }^{9}$

La paciente de este caso presentó cuadro febril durante su estancia hospitalaria, que mejoró con la administración de corticoides y antipiréticos, vía oral. $\mathrm{Al}$ alta, las lesiones remitieron y solo se evidenciaron lesiones descamativas.

La respuesta rápida y dramática del SS a los glucocorticoides sistémicos, documentada en múltiples informes de casos y series de casos, respalda su elección como tratamiento de primera línea para el SS. ${ }^{10,11}$ En los adultos, generalmente el tratamiento se inicia con prednisona oral, a una dosis de 0,5 a $1 \mathrm{mg} / \mathrm{kg} / \mathrm{d}$. Los síntomas a menudo comienzan a mejorar dentro de las 48 horas y las lesiones de la piel, generalmente, se resuelven en una a dos semanas. 


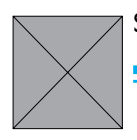

Los informes de casos y los estudios retrospectivos respaldan la eficacia de la terapia local sola en algunos pacientes con enfermedad limitada. Se utilizan corticosteroides tópicos de alta potencia (por ejemplo, clobetasol, pomada al $0,05 \%$, e inyecciones intralesionales de corticosteroides. ${ }^{12}$

\section{REFERENCIAS BIBLIOGRÁFICAS}

I. Sweet RD. Anacutefebrileneutrophilic dermatosis. Br J Dermatol. 1964; 76:349-56.

2. Marzano AV, Cugno M, Trevisan V, et al. Inflammatory cells, cytokines and matrix metalloproteinases in amicrobialpustulosis of the folds and other neutrophilic dermatoses. Int J Immunopathol Pharmacol. 20I I;24:45 I460.

3. Cohen PR. Síndrome de Sweet: una revisión exhaustiva de una dermatosis neutrofílica febril aguda. Orphanet J RareDis. 2007;2:34.

4. Hilliquin P, Marre JP, Cormier C, Renoux M, Menkes CJ, Puissant A. Síndrome de Sweet y monoartritis en un paciente con virus de inmunodeficiencia humana positivo. Arthritis Rheum. 1992;35:484-486.

5. von den Driesch P: síndrome de Sweet (dermatosis neutrofílica febril aguda). J Am Acad Dermatol. 1994;31:535-556.
6. Berger TG, Dhar A, McCalmartTH: dermatosis neutrófilas en la infección porVIH.J Am Acad Dermatol. 1994;3 I: 1045- 047.

7. Hilliquin P, Marre JP, Cormier C, Renoux M, Menkes CJ, Puissant A. Sweet'ssyndrome and monoarthritis in a human inmunodeficiency viruspositive patient. Arthritis Rheum. 1992;35: 484-6.

8. Su WP, Liu HN. Diagnostic criteria for Sweet's syndrome. Cutis. 1986;37:167-174.

9. I del Pozo, NM Malmierca, MT Yebra-Pimentel, M Almagro, W Martínez, CG Martín, E Fonseca. Síndrome de Sweet de evolución fatal asociado a síndrome de respuesta inflamatoria sistémica crónico idiopático.Actas Dermosifiliogr. 2007;98:105-8.

10. Cohen PRI, Kurzrock R. Sweet's syndrome: a review of current treatment options. Am J Clin Dermatol. 2002;3(2): I 17-3 I.

II. Mahajan VKI, Sharma NL, Sharma RC. Sweet's syndrome from an Indian perspective: a report of four cases and review of the literature. Int J Dermatol. 2006;45(6):702-8.

12. Cohen PR, Holder WR, Tucker SB, Kono S, Kurzrock R. Sweet syndrome in patients with solid tumors. Cancer. 1993;72(9):2723-3I.

\section{CORRESPONDENCIA}

alessandrapachas@gmail.com

FECHA DE RECEPCIÓN: I0 de setiembre de 2018.

FECHA DE ACEPTACIÓN: I 5 de enero de 2019.

CONFLICTO DE INTERÉs: Ninguno, según los autores.

FINANCIAMIENTO: Por los autores. 